\title{
Initial Experience in Robot Assisted Minimally Invasive Esophagectomy (RAMIE)
}

Raquel Bravo Infante ${ }^{1^{*}}$, Dulce Momblán², María Clara Arroyave ${ }^{3}$, Rafael Gerardo

Díaz del Gobbo ${ }^{4}$ and Antonio M Lacy ${ }^{5}$

${ }^{1}$ Hospital Clínic de Barcelona, Villarroel 170, 08036, Barcelona

${ }^{2}$ Hospital Clínic de Barcelona, Villarroel 170, 08036, Barcelona, Spain

${ }^{3}$ Clínica Somer, Calle 38 \#35A-54, Rionegro, Antioquia, Colombia

${ }^{4}$ Hospital Clínic de Barcelona, Villarroel 170, 08036, Barcelona, Spain

${ }^{5}$ Hospital Clínic de Barcelona, Villarroel 170, 08036, Barcelona, Spain

Received: September 12, 2017; Accepted: October 04, 2017; Published: January 02, 2018

*Corresponding author: Raquel Bravo Infante, Hospital Clínic de Barcelona, Villarroel 170, 08036, Barcelona, Spain, ORCID 000-0001-68900687, Tel: 0034932273398; E-mail: rbravo@clinic.ub.es

\section{Abstract}

Introduction: Minimally invasive esophageal surgery includes robot assisted approach. We here present our initial results of robot assisted minimally invasive esophagectomy in terms of quality of oncological resection, morbidity and mortality.

Materials and methods: Data from our first 12 consecutive patients submitted to esophagectomy by RAMIE approach were prospectively collected between November 2015 and May 2016.

Results: All our 12 patients were male patients with a median age of 64 years. Median BMI was $25 \mathrm{~kg} / \mathrm{m}^{2}$ (20-29); ASA score classification was II (83\%) and III (17\%). Tumor type was adenocarcinoma in $66.7 \%$ and squamous cell carcinoma in $33.3 \%$ of patients. Tumor location was Siewert I in $16.7 \%$, Siewert II in $8.3 \%$ and medium-distal esophagus in $75 \%$ of cases. $75 \%$ of patients received neoadjuvant treatment. Robot-assisted total esophagectomy was performed in 4 cases (33.3\%) and robot-assisted Ivor-Lewis in 8 cases (66.7\%). Conversion to thoracoscopy was necessary in one case due to pachypleuritis and there was no need to convert to open surgery. Median operating time was 320 min (210-480). Thoracic end-toend anastomosis was performed in 8 cases $(66.7 \%)$ and cervical anastomosis in 4 cases (33.3 \%). There were 2 anastomotic leaks $(17 \%)$. Resection was considered R0 in all cases. Median number of retrieved lymph nodes was 18 (6-35). Median ICU stay was 6.5 days (1-25). Median hospital stay was 13.9 days (8-28). 30-day mortality was $0 \%$.
\end{abstract}

Conclusion: Our first experience in RAMIE is acceptable, with adequate oncologic results and outcomes comparable to those of MIE.

Keywords: Robotic Esophagectomy; RAMIE; Robotic Ivor-Lewis; Esophagus cancer;

\section{Initial Experience in Robot Assisted Minimally Invasive Esophagectomy (RAMIE)}

\section{Introduction}

The treatment with curative intent for esophageal cancer remains the esophagectomy [1]. Surgical resection of the esophageal cancer is a challenging procedure compared to other gastrointestinal cancer mainly due to anatomical difficulties and association with high rates of cardiopulmonary morbidity and mortality [2,3]. Minimally invasive esophagectomy offers many advantages in comparison with open surgery: less surgical trauma, decrease in operative time, blood loss, post-operative complications, hospital stay and comparable oncological outcomes [4,5]. However, one of the main inconvenient is the learning curve associated with this technique due to the difficult dissection of the structures in a narrow space as the mediastinum $[6,7]$. Mainly the use of long instruments with limited degree of freedom and two-dimensional view can become hindrance for optimal dissection $[8,9]$. Compared to the traditional minimally invasive procedures, robotic -assisted surgery offers several 
potential advantages. One of them is that this platform can accelerate the learning curve of minimal invasive esophagectomy with the help of magnified three-dimensional view, improved articulation of instruments with seven degree of freedom, improved dexterity and enhanced ergonomics [10-12].

The two most frequent minimal invasive techniques are transhiatal esophagectomy and transthoracic esophagectomy. Transhiatal esophagectomy involves laparoscopy with blunt dissection of the esophagus (without thoracotomy or thoracosopy) and cervical esophagogastric anastomosis [13]. Ivor Lewis esophagectomy is the classic transthoracic esophagectomy, which consists of laparoscopy and right thoracotomy or thoracosopy with intrathoracic anastomosis [14]. The 3-incision McKeown approach is a modified transthoracic esophagectomy, which utilizes the right thoracic and abdominal portions of IvorLewis esophagectomy with an added left cervical anastomosis. Compared to transhiatal esophagectomy, transthoracic esophagectomy allows the removal of the intrathoracic esophageal tumor with a wider radial margin, and the oncologic resection of extensive mediastinal lymph nodes, but is associated with significant in-hospital morbidity (but not mortality), predominantly respiratory complications [15-17]. Transhiatal esophagectomy carries a lower complication rate, but only a limited lymphadenectomy can be performed with no dissection of the carinal and paratracheal lymph nodes $[16,17]$. Although no significant difference in 5-year survival was seen between the transhiatal and transthoracic esophagectomy groups, there was a trend towards survival benefit: overall survival was $29 \%$ in the transhiatal group, as compared with $39 \%$ in the transthoracic group [16].

Some limitations of the minimally invasive approaches to esophagectomy include the 2-dimensional view, decreased freedom of movement, narrow field of the mediastinum and reduced eye-hand coordination. Robotic system provides the possibility to overcome some of these limitations by offering 3-dimensional camera with $10 \times$ magnification and wristed instruments. The robotic system can be safely used during the thoracic dissection of the esophagus, gastric mobilization and intrathoracic anastomosis. It can also be used in combination with laparoscopy, hand-assisted laparoscopy or thoracoscopy. Several groups have reported their experience with robot-assisted esophagectomy. The aim of this paper is to show our preliminary experience with our first 12 robotic esophagectomies.

\section{Patients and Methods}

This is a retrospective analysis of a prospectively maintained database including the first 12 cases of robotic esophagectomy at the Hospital Clinic, Barcelona, Spain.

Patient data relevant to our analysis included age, sex, ASA score, comorbidities, BMI, tumor stage, tumor histology, adjuvant treatment, type of resection, intraoperative and postoperative complications, operative time, conversion, R status of resection, lymph node retrieval, hospital and ICU stay, morbidity, mortality and median survival.
All patients signed the informed consent and had a complete history and physical. Staging was performed in all cases with chest and abdomen CT, PET and endoscopic ultrasound.

\section{Statistical Analyses}

Descriptive statistics, including frequencies and proportions for categorical data, and means and standard deviations for continuous outcomes were calculated for all study measures.

A p value of 0.05 was considered to be statistically significant. Survival estimates were calculated using the Kaplan-Meier method. Statistical analyses were performed using SPSS 19 (SPSS, Inc) software.

\section{Operative Technique}

DWe perform the esophagectomy with the robotic platform in the thoracic part. The patient was placed in the prone position. The robotic cart was situated to the left side of the patient. The operative trocars for the robot (one 12- mm port for the assistant and three 8-mm ports for the arms) were placed. The first robotic port was inserted 1 finger-breadth below and posterior to inferior angle of scapula in the 5th or 6th intercostal space. Two 8-mm trocars were positioned under direct thoracoscopic vision in a vertical line at a distance of $5 \mathrm{~cm}$ and in triangulation with the camera port in the third and eighth intercostal spaces, respectively. One $12-\mathrm{mm}$ port for the assistant was placed between the left working port and the camera port. This was used for suction and clip/stapler application. Pneumoinsufflation was created at a pressure of $7 \mathrm{~mm} \mathrm{Hg}$. With the patient in a prone position, the esophagus falls anteriorly out of its normal position, which creates natural tension and simplifies dissection. We used Maryland bipolar forceps in left arm and hot shears (hook with monopolar current) in right arm of the robot. The procedure began with the incision of the visceral pleura between the esophagus and the lung just inferior to the azygos vein. This helped in keeping the esophagus attached to the pleura on the aortic side. More than 3 fourths of the circumference of the esophagus was mobilized in this way from the cranial to the caudal direction. The plane of dissection was outside the vagus. The posterior large direct aortic branches were then clipped, and the small branches were cauterized with bipolar forceps. This completed the mobilization of the esophagus all around. The caudal limit of the dissection was the hiatus. The same dissection was continued in the supra-azygos region. The vagal fibers going to the bronchus were preserved. The azygos vein was dissected and sectioned. Complete mobilization of the esophagus was achieved. The specimen also included the lower and middle mediastinal, subcarinal, and right paratracheal nodes. We try to identify and preserve the thoracic duct in all cases.

Stomach mobilization was done laparoscopically. All the nodes along the left gastric, paraesophageal, splenic and along the hepatic artery were removed. The stomach was mobilized on the right gastro epiploic and right gastric artery. The stomach tube was prepared intracorporially and calibrated with a bougy.

In case of Ivor-Lewis procedure, we make the esofhagus section above the azygos vein. We introduce the stomach tube 
into the chest and section it in a good zone to avoid anastomosis tension. We perform a robotic handsewn anastomosis like we show in the video.

Left supraclavicular $3 \mathrm{~cm}$ incision was taken in case of total esophagectomy with cervical anastomosis. The two heads of the sternomastoid were separated and the esophagus was pulled up to the wound. The esophagus was cut and the nasogastric tube was attached to the distal end. The specimen was removed through the cervical incision. The stomach tube was attached to the nasogastric tube and was pulled to the neck. Esophagogastric anastomosis was then done, hand-sewn or with staplers.

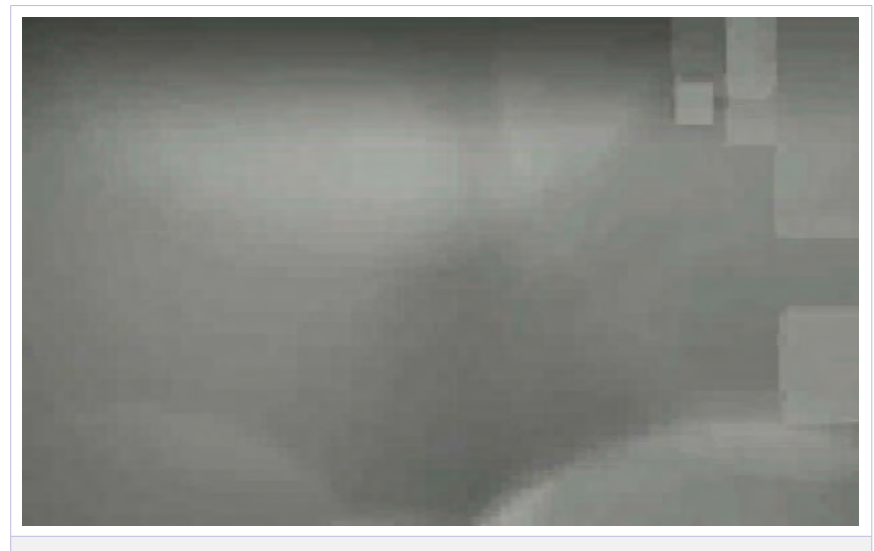

\section{Results}

From November 2015 until May 2016, a total of 12 robotassisted esophagectomies were performed in our institution. All were male patients with a median age of 64 years. Median BMI was $25 \mathrm{~kg} / \mathrm{m}^{2}$ (20-29); ASA score classification was II (83\%) and III (17\%). Tumor type was adenocarcinoma in $66,7 \%$ and squamous cell carcinoma in $33,3 \%$ of patients. Tumor was located at the mid-esophagus in 1 patient $(8.3 \%)$, at the distal esophagus in 8 patients $(66.6 \%)$ and at the esophagogastric junction in 3 patients $(25 \%)$. Eight patients $(66.6 \%)$ received neoadjuvant chemoradiotherapy and 1 patient neoadyuvant chemotherapy (8.3\%).

Robot-assisted 3-field total esophagectomy (McKeown) was performed in 4 cases (33.3\%). Robot-assisted Ivor-Lewis approach was performed in 8 cases (66.7\%). In all cases robotic assistance was used at the thoracic field for dissection and thoracic anastomosis construction. Cervical anastomosis were performed manually or stapled by conventional open approach. In 1 patient $(8.3 \%)$ conversion to transhiatal laparoscopic approach was needed due to severe pachypleuritis that precluded thoracic access. Median operating time was $320 \mathrm{~min}$ (210-480min). Mean blood loss was $280 \mathrm{ml}$. Median number of retrieved lymph nodes was 18 (6-35) and only one patient showed positive circumferential margin. Median ICU stay was 6.5 days (1-25) and median hospital stay was 13.9 days (8-28). 30day mortality was $0 \%$.

There was 1 intraoperative bleeding without consequences. Thirty-day postoperative complications were present as a total of 8 incidents (66.6\%). Pneumonia was the most commonly observed event ( 3 cases, $25 \%$ ) followed by anastomotic leak (2 cases, $16.6 \%)$. Also there were a case of atelectasis $(8.3 \%)$, one of pleural effusion (8.3\%) and one of pneumothorax (8.3\%). Late complications were present in 4 patients: 2 cases of anastomotic stricture $(16.6 \%)$ and 2 cases of recurrent nerve palsy, one temporary $(8.3 \%)$ and one permanent $(8.3 \%)$ (See table 1 for morbidity assessment). At the end of the study period, 10 patients $(83.3 \%)$ were alive in disease free stage at the median follow up of 18 months. There was a patient who dead due to disease progression. Also there was a patient alive but with disease progression. Figure 1 shows the Kaplan Meier survival analysis.

\begin{tabular}{|c|c|}
\hline \multicolumn{1}{|l|}{ Table 1: Morbidity assessment } & $\mathbf{n}(\mathbf{\%})$ \\
\hline INTRAOPERATIVE & $\mathbf{1}(\mathbf{8 . 3} \%)$ \\
\hline Bleeding & $1(8.3 \%)$ \\
\hline 30- DAY POSTOPERATIVE (Clavien Dindo) & $\mathbf{8}(\mathbf{6 6 . 6} \%)$ \\
\hline Anastomotic leak (III) & $2(16.6 \%)$ \\
\hline Pneumonia (II) & $3(25 \%)$ \\
\hline Atelectasia (I) & $1(8.3 \%)$ \\
\hline Pleural Efussion (I) & $1(8.3 \%)$ \\
\hline Pneumothorax (IIIa) & $1(8.3 \%)$ \\
\hline AATE COMPLICATIONS & $\mathbf{4}(\mathbf{3 3 . 3} \%)$ \\
\hline Anastomotic stricture & $2(16.6 \%)$ \\
\hline & 1 temporary (8.3\%) \\
\hline
\end{tabular}

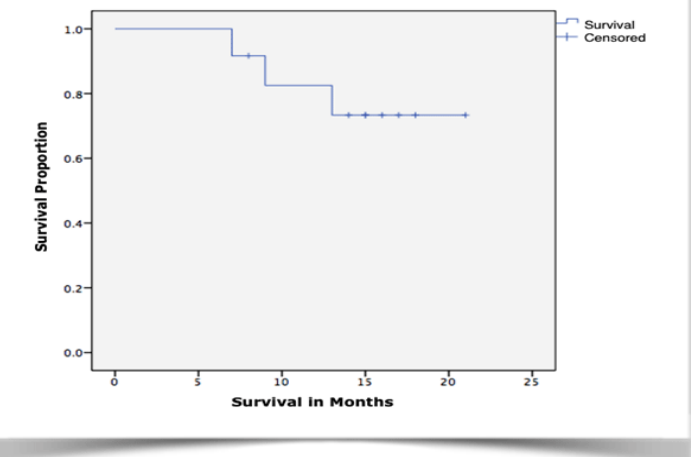

Figure 1: Survival

\section{Discussion}

Esophagectomy is one of the most complex procedures of gastro-intestinal surgery with a high postoperative morbidity and mortality mainly because of respiratory complications [18]. The potential advantages of minimally invasive procedures, especially regarding a decrease in pulmonary complications, have been studied for the last 4 decades [19]. Minimally Invasive Esophagectomy (MIE) includes conventional pure laparoscopy/ thoracoscopy, hybrid procedures (celiotomy/thoracotomy; 
celiotomy/thoracoscopy), hand-assisted surgery and, more recently, robot-assisted esophagectomy. Some aspects such as oncological outcomes, anastomosis location or patient positioning are, however, controversial. To date, there are only a few papers reporting long-term oncological outcomes and they have a short follow-up and a small number of patients, but they have failed, so far, to show benefits compared to open esophagectomy $[20,21]$. Patient positioning influences the MIE technique. Left lateral decubitus position has been more frequently used, although Prone Decubitus Position (PDP) is now been increasingly used. However, recent studies comparing both positions show that PDP provides some advantages such as better lung ventilation and surgical field exposure, leading to improved postoperative outcomes [22,23].

Some limitations of MIE can be overcome with the aid of robotic systems, which provide some advantages in small surgical fields, with fewer instrument exchanges in the thoracic phase of an esophagectomy. The first robot-assisted MIE using the Da Vinci system was first published by Kernstine, et al. [24] in 2004. A few short series, between 6 and 47 cases, have been reported since then, with anastomosis at the cervical level in all cases [25-29] The first robot-assisted Ivor Lewis series were published after 2013, reporting 22 (30), 17 (31), and 50 (32) cases, respectively, with all patients in lateral decubitus position. In 2014 Trugeda et al. published the first series of robot-assisted Ivor Lewis in PDP with intrathoracic manual anastomosis [33]. We agree with this group on that PDP makes the dissection and lymphadenectomy easier, in an optimal field, although a stapled anastomosis, either transthoracic or transoral, is more difficult when this access is used. Robotic assistance makes manual intrathoracic anastomosis easier and faster and allowed us to use the prone position and its potential advantages without affecting oncological outcomes. In PDP we are able to use just three of the four arms of the robotic system achieving a more cost-effective procedure and decreasing space conflicts.

In two published series about robotic esophagectomy with intrathoracic anastomosis, leakage rate was 4.5 and $2 \%$ [30,32]. Nevertheless, Sarkaria, et al. [31] reported an anastomotic leakage and tracheo esophageal fistula rate of $14 \%$ and $14 \%$ respectively. Trugeda, et al. [34] reported a leakage rate of $21.9 \%$ in a study including intrathoracic and cervical anastomosis.

Some studies show a rising rate of chylous leak with the introduction of minimal invasive esophagectomy, from $2.4 \%$ showed by Smithers, et al. [35] to $11.6 \%$ by Luketich, et al. [36]. No chylous leak appeared in our series. Our patients take whole milk and butter the night before the surgery. This way we can identify and preserve the chylous duct easier.

Despite these potential advantages, evidence showing any clear superiority of the robot-assisted MIE over conventional thoracoscopic esophagectomy is still very limited. Since 2012 a single center controlled randomized trial has been ongoing in the Netherlands to compare robot-assisted and open esophagectomies, with 112 patients (56 per arm) and a followup of 5 years. However, for stronger evidence, multicentric trials with a large number of patients are needed [37].

\section{References}

1. Mariette C, Piessen G, Triboulet JP. Therapeutic strategies in oesophageal carcinoma: role of surgery and other modalities. Lancet Oncol. 2007;8(6):545-553.

2. Law $\mathrm{S}$, Wong J. Use of minimally invasive oesophagectomy for cancer of the oesophagus. Lancet Oncol. 2002;3(4):215-222.

3. Kim T, Hochwald SN, Sarosi GA, Caban AM, Rossidis G, Ben-David K. Review of minimally invasive esophagectomy and current controversies. Gastroenterol Res Pract. 2012;2012:683213. doi: $10.1155 / 2012 / 683213$

4. Nafteux P, Moons J, Coosemans W, Decaluwé H, Decker G, De Leyn P, et al. Minimally invasive oesophagectomy: a valuable alternative to open oesophagectomy for the treatment of early oesophageal and gastro-oesophageal junction carcinoma. Eur J Cardiothorac Surg. 2011;40(6):1455-1463. discussion 1463-1464. doi: 10.1016/j. ejcts.2011.01.086.

5. Verhage RJ, Hazebroek EJ, Boone J, Van Hillegersberg R. Minimally invasive surgery compared to open procedures in esophagectomy for cancer: a systematic review of the literature. Minerva Chir. 2009;64(2):135-146.

6. Law S. Minimally invasive techniques for oesophageal cancer surgery. Best Pract Res Clin Gastroenterol. 2006;20(5):925-940.

7. Finley DS, Nguyen NT. Surgical robotics. Curr Surg. 2005;62(2):262272.

8. Germain A, Bresler L. Robotic-assisted surgical procedures in visceral and digestive surgery. J Visc Surg. 2011;148(5 Suppl):e40-e46.

9. Ruurda JP, van Vroonhoven TJ, Broeders IA. Robot-assisted surgical systems: a new era in laparoscopic surgery. Ann R Coll Surg Engl. 2002;84(4):223-226.

10. van Hillegersberg R, Boone J, Draaisma WA, Broeders IA, Giezeman MJ, Borel Rinkes IH. First experience with robot-assisted thoracoscopic esophagolymphadenectomy for esophageal cancer. Surg Endosc. 2006;20(9):1435-1439.

11. Kernstine $\mathrm{KH}$. The first series of completely robotic esophagectomies with three-field lymphadenectomy: initial experience. Surg Endosc. 2008;22(9):2102-2102.

12. Puntambekar SP, Rayate N, Joshi S, Agarwal G. Robotic transthoracic esophagectomy in the prone position: experience with 32 patients with esophageal cancer. J Thorac Cardiovasc Surg. 2011;142(5):12831284. doi: $10.1016 /$ j.jtcvs.2011.03.028

13. Turner GG. Carcinoma of the Esophagus: the Question of Its Treatment By Surgery. 1936;227(5864):130-134.

14. Lewis I. The surgical treatment of carcinoma of the oesophagus; with special reference to a new operation for growths of the middle third. Br J Surg. 1946;34:18-31.

15. Mathisen DJ, Grillo HC, Wilkins EW Jr, Moncure AC, Hilgenberg AD. Transthoracic esophagectomy: a safe approach to carcinoma of the esophagus. Ann Thorac Surg. 1988;45(2):137-143.

16. Hulscher JB, van Sandick JW, de Boer AG, Wijnhoven BP, Tijssen JG, Fockens $\mathrm{P}$, et al. Extended transthoracic resection compared with limited transhiatal resection for adenocarcinoma of the esophagus. $\mathrm{N}$ Engl J Med. 2002;347(21):1662-1669.

17. Hulscher JB, Tijssen JG, Obertop H, van Lanschot JJ. Transthoracic versus transhiatal resection for carcinoma of the esophagus: a metaanalysis. Ann Thorac Surg. 2001;72(1):306-313. 
18. Markar SR, Karthikesalingam A, Thrumurthy S, Low DE. Volumeoutcome relationship in surgery for esophageal malignancy: systematic review and meta-analysis 2000-2011. J Gastrointest Surg. 2012;16(5):1055-1063. doi: 10.1007/s11605-011-1731-3

19. Tsujimoto H, Takahata R, Nomura S, Yaguchi Y, Kumano I, Matsumoto $\mathrm{Y}$, et al. Video-assisted thoracoscopic surgery for esophageal cancer attenuates postoperative systemic responses andnpulmonary complications. Surgery. 2012;151(5):667-673. doi: 10.1016/j. surg.2011.12.006

20. Osugi H, Takemura M, Higashino M, Takada N, Lee S, Kinoshita $H$ A comparison of video-assisted thoracoscopic oesophagectomy and radical lymph node dissection for squamous cell cancer of the oesophagus with open operation. Br J Surg. 2003;90(1):108-113.

21. Smithers BM, Gotley DC, Martin I, Thomas JM. Comparison of the outcomes between open and minimally invasive esophagectomy. Ann Surg. 2007;245(2):232-240.

22. Jarral OA, Purkayastha S, Athanasiou T, Darzi A, Hanna GB, Zacharakis E. Thoracoscopic esophagectomy in the prone position. Surg Endosc. 2012;26(8):2095-2103.

23. Tanaka E, Okabe H, Kinjo Y, Tsunoda S, Obama K, Hisamori S, Sakai Y. Advantages of the prone position for minimally invasive esophagectomy in comparison to the left decubitus position: better oxygenation after minimally invasive esophagectomy. Surg Today. 2015;45(7):819-825. doi: 10.1007/s00595-014-1061-7

24. Kernstine KH, DeArmond DT, Karimi M, Van Natta TL, Campos JH, Yoder MR, et al. The robotic, 2-stage, 3-field esophagolymphadenectomy. J Thorac Cardiovasc Surg. 2004;127(6):1847-1849.

25. Bodner JC, Zitt M, Ott H, Wetscher GJ, Wykypiel H, Lucciarini P, et al. Robotic-assisted thoracoscopic surgery (RATS) for benign and malignant esophageal tumors. Ann Thorac Surg. 2005;80(4):12021206.

26. Boone J, Schipper ME, Moojen WA, Borel Rinkes IH, Cromheecke GJ, van Hillegersberg R. Robot-assisted thoracoscopic oesophagectomy for cancer. Br J Surg. 2009;96(8):878-886. doi: 10.1002/bjs.6647

27.van Hillegersberg R, Boone J, Draaisma WA, Broeders IA, Giezeman MJ, Borel Rinkes IH. First experience with robotassisted thoracoscopic esophagolymphadenectomy for esophageal cancer. Surg Endosc. 2006;20(9):1435-1439.
28. Kim DJ, Hyung WJ, Lee CY, Lee JG, Haam SJ, Park IK, et al. Thoracoscopic esophagectomy for esophageal cancer: feasibility and safety of robotic assistance in the prone position. J Thorac Cardiovasc Surg. 2010;139(1):53-59.e1. doi: 10.1016/j.jtcvs.2009.05.030

29. Suda K, Ishida Y, Kawamura Y, Inaba K, Kanaya S, Teramukai S, et al. Robot-assisted thoracoscopic lymphadenectomy along the left recurrent laryngeal nerve for esophageal squamous cell carcinoma in the prone position: technical report and shortterm outcomes. World J Surg. 2012;36(7):1608-1616. doi: 10.1007/s00268-012-1538-8

30. Cerfolio RJ, Bryant AS, Hawn MT. Technical aspects and early results of robotic esophagectomy with chest anastomosis. J Thorac Cardiovasc Surg. 2013;145(1):90-96. doi: 10.1016/j.jtcvs.2012.04.022

31. Sarkaria IS, Rizk NP, Finley DJ, Bains MS, Adusumilli PS, Huang J, et al. Combined thoracoscopic and laparoscopic robotic-assisted minimally invasive esophagectomy using a fourarm platform: experience, technique and cautions during early procedure development. Eur J Cardiothorac Surg. 2013;43(5):e107-e115.

32. de la Fuente SG, Weber J, Hoffe SE, Shridhar R, Karl R, Meredith KL. Initial experience from a large referral center with roboticassisted Ivor Lewis esophagogastrectomy for oncologic purposes. Surg Endosc. 2013;27(9):3339-3347. doi: 10.1007/s00464-013-2915-6

33. Trugeda S, Fernández-Díaz MJ, Rodríguez-Sanjuán JC, Palazuelos CM, Fernández-Escalante $\mathrm{C}$, Gómez-Fleitas $\mathrm{M}$. Initial results of robotassisted Ivor-Lewis oesophagectomy with intrathoracic handsewn anastomosis in the prone position. Int J Med Robot. 2014;10(4):397403. doi: $10.1002 /$ rcs. 1587

34. Trugeda Carrera MS, Fernández-Díaz MJ, Rodríguez-SanjuánJC, Manuel-Palazuelos JC, de Diego García EM, Gómez-Fleitas M. [Initial results of robotic esophagectomy for esophageal cancer]. Cir Esp. 2015;93(6):396-402. doi: 10.1016/j.ciresp.2015.01.002

35. Smithers BM, Gotley DC, McEwan D, Martin Bessell IJ, Doyle L. Thoracoscopic mobilization of the esophagus: A 6-year experience. Surg Endosc. 2001;15(2):176-182.

36. Luketich JD, Alvelo-Rivera M, Buenaventura PO,Christie NA, McCaughan JS, Litle VR, et al. Minimally invasive esophagectomy: Outcomes in 222 patients. Ann Surg. 2003;238(4):486-495; discussion 494-495.

37. van der Sluis PC, Ruurda JP, van der Horst S, Verhage RJ, Besselink MG, Prins MJ, et al. Robotassisted minimally invasive thoraco-laparoscopic esophagectomy versus open transthoracic esophagectomy for resectable esophageal cancer, a randomized controlled trial (ROBOT trial). Trials. 2012;13:230. doi: 10.1186/1745-6215-13-230 